\title{
МОДЕЛЬ ВЛИЯНИЯ СТРУКТУРЫ ИНВЕСТИЦИЙ НА РЕЗУЛЬТАТЫ СТРОИТЕЛЬНОЙ ДЕЯТЕЛЬНОСТИ
}

\section{(c) 2020 Юй Цзинчэнь}

аспирант, кафедра экономики и управления предприятиями и производственными комплексами Санкт-Петербургский государственный экономический университет, Россия, Санкт-Петербург

E-mail: may_9171@mail.ru

В статье определены особенности прямых иностранных инвестиций в строительной сфере России. Проанализирована динамика и структура прямых иностранных инвестиций в строительной сфере России. Выявлена модель зависимости влияния структуры инвестиций на результаты строительной деятельности

Ключевые слова: прямые иностранные инвестиции, строительство, динамика, структура

В условиях присутствия России в ВТО, продолжающихся процессов глобализации и расширения сфер влияния транснациональных компаний, роль прямых иностранных инвестиций в экономическом развитии страны продолжает расти. Значительный объем таких инвестиционных потоков поступает в строительный сектор, поскольку строительство традиционно являлось производственно-капиталоемким районом, развивающимся в сочетании со многими другими секторами экономики. Это инфраструктурные проекты, промышленное строительство, гражданское строительство и многое другое. Строительство объектов зачастую является не основной целью, а скорее следствием создания других активов, комплексов недвижимости.

Прямые иностранные инвестиции - это физические инвестиции и закупки, осуществляемые компанией в иностранном государстве, как правило, путем открытия заводов и покупки зданий, машин, заводов и другого оборудования в иностранном государстве. Эти виды инвести- ций находят гораздо большую поддержку, поскольку они обычно считаются долгосрочными инвестициями и помогают укрепить экономику иностранного государства [1].

Рассмотрим динамику прямых иностранных инвестиций в строительстве России за 20102018 г.г. (табл. 1, рис. 1).

Согласно данным рисунка 1 , можно сделать вывод, что начиная с 2012 года динамика поступлений прямых иностранных инвестиций в Россию сохраняет отрицательный характер. Исключением является только 2017 год, когда значение прямых иностранных инвестиций составило 3214 млн. дол. США. В период с 2010 по 2014 г.г., динамика была не стабильной, так как значения поступлений прямых иностранных инвестиций постоянно менялись, от большего к меньшему, и наоборот. В 2018 году число прямых иностранных инвестиций составило 1427 млн. дол. США., что на 1787 млн. дол. США. меньше 2017 года, что свидетельствует о дальнейшей тенденции к снижению.

Таблица 1. Динамика прямых иностранных инвестиций в строительстве России за 2010-1018 г.г. [2]

\begin{tabular}{|c|c|c|c|c|c|c|c|c|c|c|c|c|c|c|c|c|c|c|c|c|c|c|c|c|c|c|}
\hline \multicolumn{3}{|c|}{2010} & \multicolumn{3}{|c|}{2011} & \multicolumn{3}{|c|}{2012} & \multicolumn{3}{|c|}{2013} & \multicolumn{3}{|c|}{2014} & \multicolumn{3}{|c|}{2015} & \multicolumn{3}{|c|}{2016} & \multicolumn{3}{|c|}{2017} & \multicolumn{3}{|c|}{2018} \\
\hline 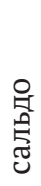 & 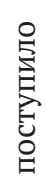 & 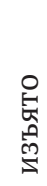 & $\begin{array}{l}\text { 어 } \\
\hat{0} \\
\text { త్ర }\end{array}$ & 疍 & 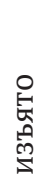 & $\begin{array}{l}\text { ㅇ } \\
\text { 会 } \\
\text { త }\end{array}$ & 空 & 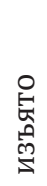 & $\begin{array}{l}\text { 어 } \\
\text { 量 } \\
\text { తુ }\end{array}$ & 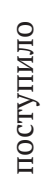 & 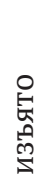 & 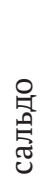 & 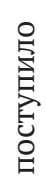 & 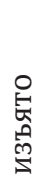 & 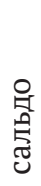 & 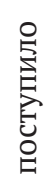 & $\begin{array}{l}\text { O } \\
\stackrel{E}{E} \\
\stackrel{5}{0} \\
\stackrel{0}{S}\end{array}$ & 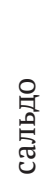 & 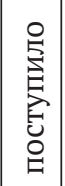 & 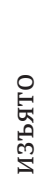 & 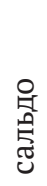 & 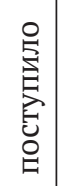 & $\begin{array}{l}\text { O } \\
\stackrel{E}{E} \\
\text { 今 } \\
\stackrel{M}{S}\end{array}$ & 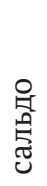 & 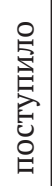 & 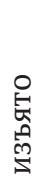 \\
\hline 芴 & $\begin{array}{l}0 \\
10 \\
\infty \\
\text { in }\end{array}$ & $\begin{array}{l}\text { no } \\
\text { int }\end{array}$ & N & $\begin{array}{l}\text { M } \\
\text { M } \\
\text { no }\end{array}$ & 离 & $\begin{array}{l}\infty \\
\sim \\
\sim \\
M\end{array}$ & $\begin{array}{l}0 \\
\stackrel{1}{1} \\
6\end{array}$ & $\begin{array}{l}\infty \\
\underset{\infty}{\infty} \\
\sim\end{array}$ & $\begin{array}{l}\text { 으 } \\
\infty \\
\text { N }\end{array}$ & 尽 & $\begin{array}{l}0 \\
\infty \\
\sim \\
\sim\end{array}$ & $\stackrel{\infty}{\underset{N}{N}}$ & 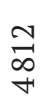 & $\begin{array}{l}\text { \& } \\
\text { ㄱ }\end{array}$ & $\begin{array}{l}\text { 능 } \\
\stackrel{1}{1}\end{array}$ & $\begin{array}{l}\infty \\
\stackrel{\infty}{\circ} \\
\stackrel{1}{N}\end{array}$ & $\underset{M}{\stackrel{\overbrace{}}{M}}$ & $\underset{\sim}{*}$ & $\begin{array}{l}\mathcal{M} \\
\mathscr{2} \\
\sim\end{array}$ & $\begin{array}{l}\text { กิ } \\
\text { กิ }\end{array}$ & $\begin{array}{l}\text { N } \\
\stackrel{ }{N}\end{array}$ & $\begin{array}{l}\Delta \\
\stackrel{J}{N}\end{array}$ & $\underset{\beth}{\stackrel{\Xi}{二}}$ & $\underset{i}{\stackrel{\leftrightarrows}{t}}$ & 今ે & 강 \\
\hline
\end{tabular}




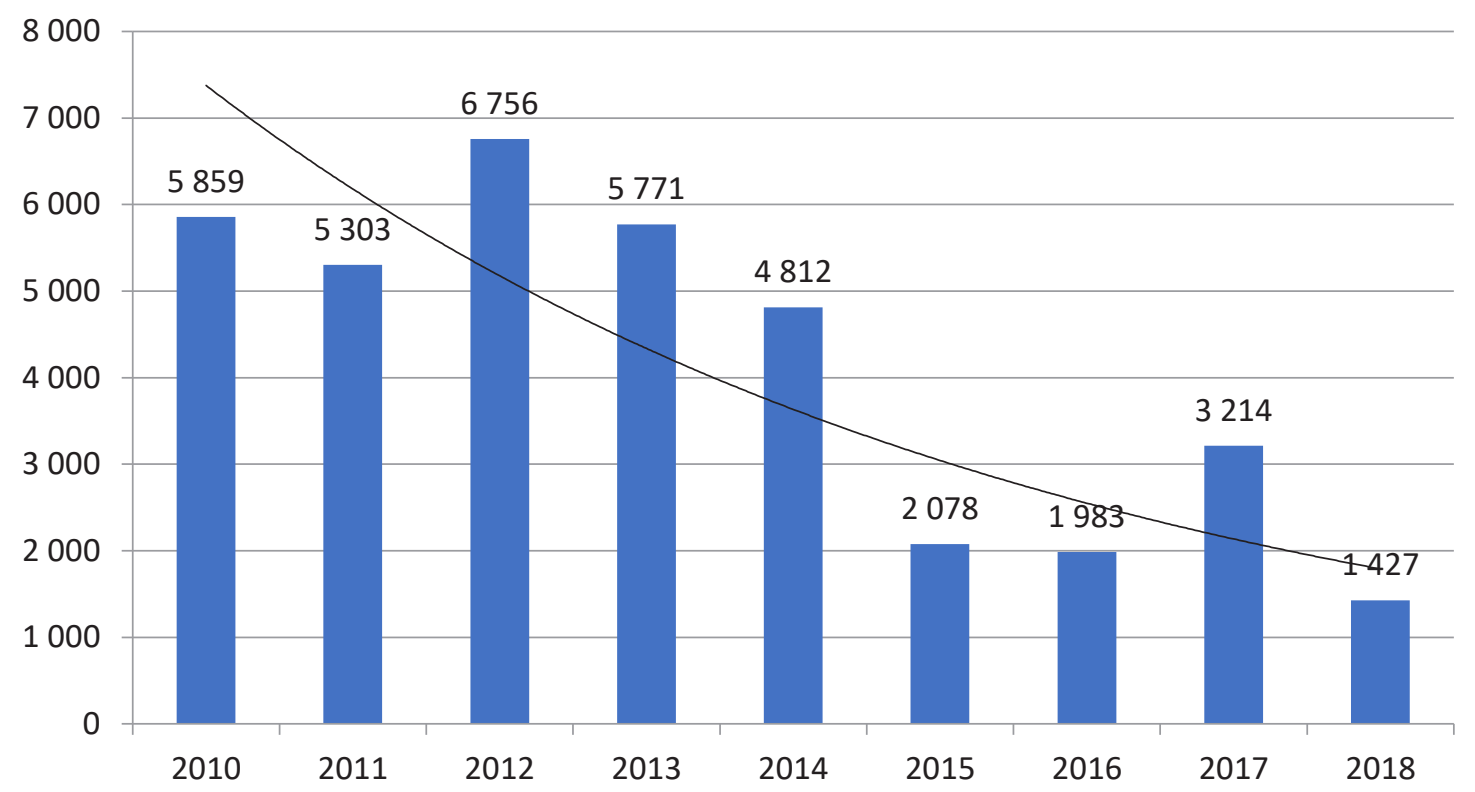

Puc. 1. Динамика ПИИ в строительстве России за 2010-2018 г.г. (млн. дол. США.) [2]

Следовательно, определим алгоритм зави- кредиторов, клиентов, покупателей и т.д. (юрисимости влияния структуры инвестиций на результаты строительной деятельности.

дические и физические лица);

- производители инвестиционных фондов

Модель взаимодействия прямых иностранных инвестиций и строительной деятельности приведена на рис. 2.

В инвестиционно-строительной деятельности принимают участие следующие субъекты:

- застройщики (юридические лица и люди, владеющие землей под застройку);

- инвесторы, которые выступают в качестве (материалы, технологии, технологии и т.д.);

- строительные и монтажные компании, которые превращают инвестиционные ресурсы в основные средства. Строительно-монтажные организации объединяют деятельность инвесторов, заказчиков, поставщиков материалов и технических ресурсов.

- инновационные организации, разрабаты-

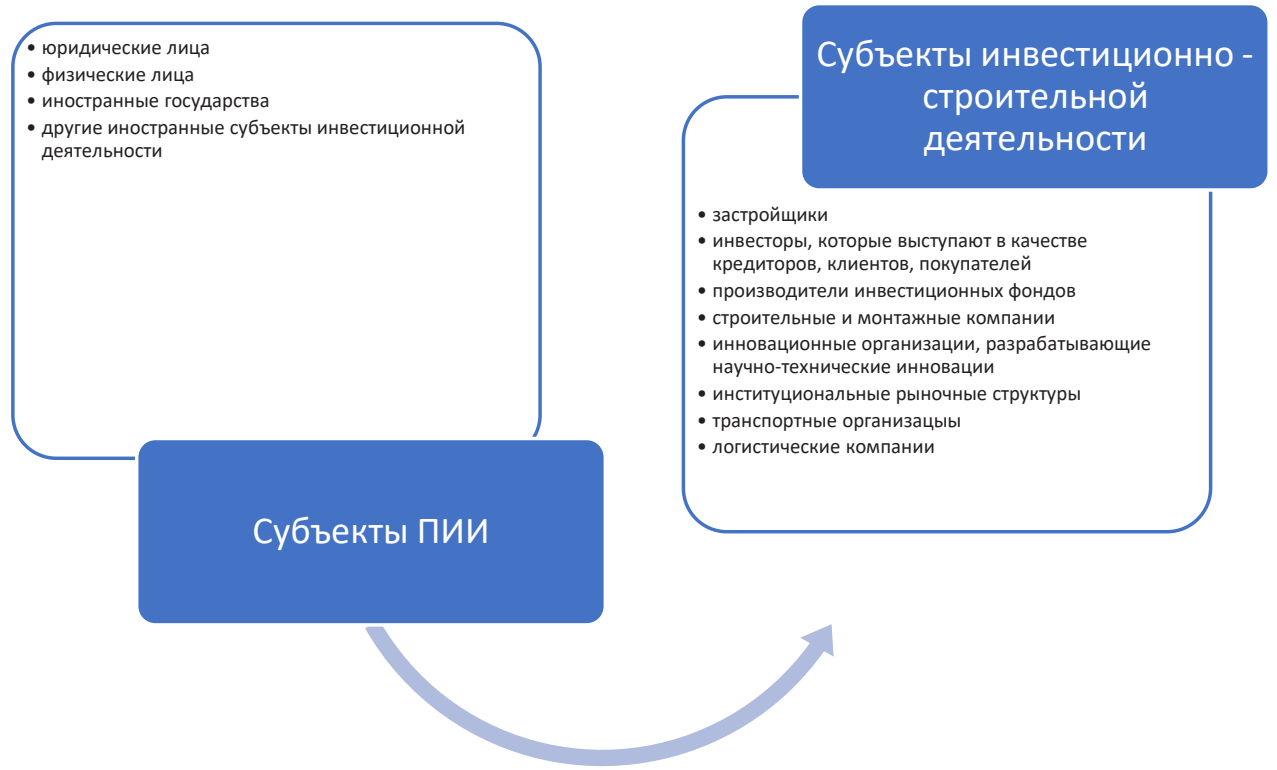

Puc. 2. Модель взаимодействия прямых иностранных инвестиций и строительной деятельности Составлено автором 
Таблица 2. Расчетная таблица уравнения регрессии

\begin{tabular}{|c|c|c|c|c|c|c|c|c|}
\hline & $\begin{array}{c}\text { Коэффи- } \\
\text { циенты }\end{array}$ & $\begin{array}{c}\text { Cтан- }^{-} \\
\text {дартная } \\
\text { ошибка }\end{array}$ & $\begin{array}{l}\text { t-стати- } \\
\text { стика }\end{array}$ & $\begin{array}{c}\text { Р-Значе- } \\
\text { ние }\end{array}$ & $\begin{array}{c}\text { Нижние } \\
95 \%\end{array}$ & $\begin{array}{c}\text { Верхние } \\
95 \%\end{array}$ & $\begin{array}{c}\text { Нижние } \\
95,0 \%\end{array}$ & $\begin{array}{c}\text { Верхние } \\
95,0 \%\end{array}$ \\
\hline Y-пересечение & 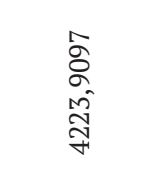 & 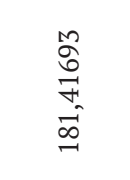 & 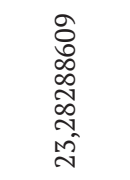 & 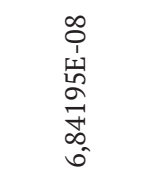 & 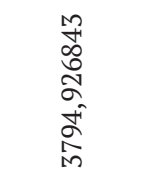 & 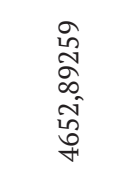 & 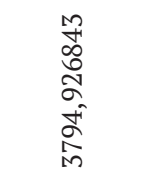 & 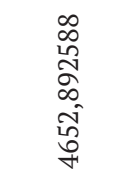 \\
\hline Переменная X 1 & $\begin{array}{l}\mathbb{H} \\
\text { 足 } \\
0 \\
0 \\
0 \\
1\end{array}$ & $\begin{array}{l}\text { Ln } \\
0 \\
o \\
o \\
\sigma \\
\text { 今. } \\
0 \\
0\end{array}$ & 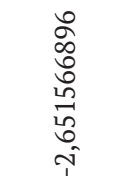 & $\begin{array}{l}\infty \\
0 \\
0 \\
0 \\
0 \\
\infty \\
\tilde{0} \\
0 \\
0\end{array}$ & 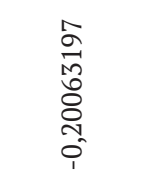 & $\begin{array}{l}\infty \\
\stackrel{0}{+} \\
\stackrel{+}{0} \\
\text { o } \\
0 \\
1\end{array}$ & 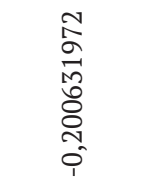 & $\begin{array}{l}\text { oे } \\
0 \\
\stackrel{0}{f} \\
\stackrel{+}{0} \\
0 \\
0\end{array}$ \\
\hline
\end{tabular}

вающие научно-технические инновации для их последующего использования при создании инвестиционного капитала;

- институциональные рыночные структуры, обеспечивающие обращение инвестиций в области их производственного использования в форме инвестиционного капитала;

- логистические компании, которые обеспечивают наполнение распределительной сети и предоставляют товары и услуги для хозяйствующих субъектов от инвестиционной и строительной деятельности;

- транспортные организации и т.д. [1]

Существуют различные аналитические приемы определения коэффициента корреляции (r). Расчет зависимости прямых иностранных инвестиций и строительной деятельности будут проведены с помощью следующей:

$$
r=\frac{\frac{1}{n-1} \sum_{i=1}^{n}\left(x_{i}-\bar{x}\right)\left(y_{i}-\bar{y}\right)}{S_{x} S_{y}}
$$

где $\mathrm{S}_{\mathrm{x}}$ и $\mathrm{S}_{\mathrm{y}}$ - среднеквадратичное отклонение соответственно для каждого рассматриваемого массива чисел; $\mathrm{x}_{\mathrm{i}}$ и $\mathrm{y}_{\mathrm{i}}-$ текущие значения единиц обеих совокупностей; $\bar{x}$ и $\bar{y}-$ их средние величины и $\mathrm{n}-$ число измерений (элементов) в каждой совокупности. Рассчитаем данные с помощью программы Excel. Значение $\mathrm{x}-$ примем как динамику ПИИ в строительстве России, значение у - уровень ВВП по ППС России [3] за 2010-2018 г.г. (табл. 2).

Согласно таблице 2, можно сделать вывод, что в исследуемой ситуации $50,1 \%$ общей вариабельности значения ВВП по ППС России объясняется изменением динамика ПИИ в строительстве России. Влияние структуры инвестиций на результаты строительной деятельности имеет прямой характер. Это объясняет то, что при изменении структуры инвестиций в строительство России, прямо повлияет на аналогичное изменение результатов строительной деятельности России.

Таким образом, необходимо разработать целенаправленные меры для управления прямыми иностранными инвестициями, для того, чтобы повысить их мультиплицирующий эффект, и, следовательно с учетом разработки мер по их защите, станет возможным и повышение притока инвестиций в отрасль строительства, где они крайне необходимы, и в целом в экономику.

\section{Библиографический список}

1. Ермолов Е. Е. Прямые иностранные инвестиции в строительстве.- Вестник университета. № 23. - 2013. - c. 32-36.

2. Прямые инвестиции в Российскую Федерацию по субъектам, в которых зарегистрированы резиденты (участие в капитале, реинвестирование доходов, долговые инструменты). URL: https://fedstat.ru/opendata/7702 235133-fiveafiveasixatwoafive

3. Показатель Российской Федерации - ВВП-по-ППС. Knoеma. Мировой атлас данных. - URL: https://knoema. ru/atlas/embed/Российская-Федерация/ВВП-по-ППС 